\title{
Extração e comercialização do óleo de andiroba (Carapa guianensis Aublet.) na comunidade da Ilha das Onças, no município de Barcarena, Pará, Brasil
}

\author{
Extraction and commercialization of Crabwood oil (Carapa guianensis Aublet.)
} in the Island of Onças community in the municipality of Barcarena, Pará, Brazil

Extracción y comercialización del aceite andiroba (Carapa guianensis Aublet.) en la comunidad Isla de las Onzas en el municipio Barcarena, Pará, Brasil

\author{
Ronaldo Lopes de Sousa ${ }^{1}$ \\ Abdi Ueke da Silva Miranda ${ }^{1}$ \\ Yvens Ely Martins Cordeiro ${ }^{1}$ \\ Maria das Graças Pereira ${ }^{1}$
}

\begin{abstract}
Resumo: Os extratores de óleo das sementes de andiroba residentes na comunidade da Ilha das Onças adotam o processo tradicional de extração, e o tempo empregado para obter o produto final foi de, em média, 42 dias. Os extratores tinham mais de 40 anos, a transmissão do conhecimento se deu dentro da família e a comercialização do produto ocorreu nas feiras de Barcarena e Ver-o-Peso, Belém.
\end{abstract}

Palavras-chave: Ilha das Onças; óleo de andiroba; comunidade de extratores.

Abstract: The oil extractors of andiroba seeds resident in the community of Island of Onças adopt the traditional extraction process, and the time taken to obtain the final product was on average, 42 days. The extractors were more than 40 years old, the transmission of knowledge occurred within the family and the commercialization of the product took place at the fairs of Barcarena and Ver-o-Peso, Belém.

Keywords: Ilha das Onças; oil of crabwood; extractors community.

Resumen: Los extractores de aceite de las semillas de andiroba residentes en la comunidad de la Isla de Onzas adopta el proceso tradicional de extracción, y el tiempo empleado para obtener el producto final fue de promedio, 42 dias. Los extractores tenían más de 40 años, la transmisión del conocimiento se dio dentro de la familia y la comercialización del producto ocurrió en las ferias de Barcarena y Ver-o-Peso, Belém.

Palabras clave: Ilha das Onças; aceite de andiroba; comunidad de extractores.

\section{INTRODUÇÃO}

A floresta amazônica é exuberante e diversificada, representando a maior cobertura vegetal do mundo, com aproximadamente 14.003 espécies (CARDOSO et al., 2017). Entre elas, encontra-se a andirobeira (Carapa guianensis Aublet, Carapa procera D.C), que se desenvolve preferencialmente em ecossistema de várzea, mas também cresce em floresta de terra firme (MENDONÇA; FERRAZ, 2007; SANTOS et al., 2014).

A C. guianensis Aublet (Meliaceae) é considerada uma das espécies mais valiosas pelos ribeirinhos amazônidas, sendo a madeira usada na construção de casas, móveis e embarcações, enquanto as sementes servem para extração de óleo (MENDONÇA; FERRAZ, 2007). O óleo é amplamente utilizado na medicina popular pelos moradores das comunidades ribeirinhas (LEANDRO; JARDIM; GAVILANES, 2017; OLIVEIRA; BRAGA, 2017), por possuir ampla atividade biológica, bem como ação de analgésico (PENIDO et al., 2005), antibacteriano (SILVA; OLIVEIRA; FIGUEREDO, 2009), anti-inflamatório (PENIDO et al., 2006), antifúngico (FERREIRA et al., 2015), antialérgico (FERRARIS et al., 2011), antimalárico (PEREIRA et al., 2014), além de se mostrar eficaz também contra feridas,

\footnotetext{
${ }^{1}$ Universidade Federal do Pará (UFPA), Abaetetuba, Pará, Brasil.
} 
hematomas, úlceras de herpes, reumatismo e infecções de ouvido, e como repelente contra picadas de insetos (NAYAK et al., 2011; MIRANDA JÚNIOR et al., 2012, PROPHIRO et al., 2012).

A extração do óleo pode ser realizada através da prensagem mecânica ou de forma tradicional. Essa última modalidade é adotada, geralmente, pelos extratores de comunidades que não possuem eletricidade e sofrem carência dos serviços públicos. Segundo Mendonça e Ferraz (2007), o processo tradicional de extração do óleo de andiroba pode ser dividido em três etapas: coleta e seleção das sementes, preparo da massa e extração do óleo. Entretanto, quanto ao rendimento da produção de óleo, há discrepâncias nos relatos, devido à falta de padronização nos procedimentos de extração, o que leva a variações de 2 a $30 \mathrm{~kg}$ de sementes para se obter um litro de óleo (PLOWDEN, 2004; MENDONÇA; FERRAZ, 2007; SILVA et al., 2010).

A produção final do óleo de andiroba é destinada ao consumo próprio ou para comercialização. Esse produto serve de insumo para as indústrias cosméticas, farmacêuticas, alimentícias e têxteis, fazendo parte da composição de perfumes, produtos de higiene pessoal e de beleza, corantes e alimentos funcionais (BRASIL, 2015). Embora o óleo extraído das sementes da andirobeira tenha tantas finalidades, gera pouca renda para as comunidades extratoras, devido a fatores como cadeia produtiva bastante simplificada, falta de conhecimento do mercado consumidor, dificuldades para organizar associação comunitária e produção sazonal, que dificulta a oferta regular do produto (SANTOS; GUERRA, 2010).

O presente trabalho teve como objetivo compreender como as famílias extratoras de óleo de andiroba da comunidade da Ilha das Onças, localizada no município de Barcarena, Pará, realizavam a produção e a comercialização do óleo extraído das sementes de andiroba.

\section{MATERIAIS E MÉTODOS}

\subsection{0 local da pesquisa}

O município de Barcarena (S 0130'21" e W 4837'33") pertence à mesorregião metropolitana de Belém. É limitado em grande parte pela baía de Marajó e recortado por inúmeros rios, furos e igarapés, caracterizando-se como área de estuário (SOUZA; LISBOA, 2005). A área total do município é de $1.316,2 \mathrm{Km}^{2}$ e seu território é dividido por pequenas ilhas, tais como Ilha do Arapari, da Mucura, do Arapiranga, das Onças, entre outras (CARMO; COSTA, 2016). Os estudos da flora no município de Barcarena se referem a um levantamento botânico de espécies usadas com fins terapêuticos (AMOROZO; GÉLY, 1988), ao estudo de macrófitas aquáticas (LINS et al., 1989) e a um levantamento etnobotânico (AMOROZO, 1997).

A Ilha das Onças faz parte do município de Barcarena e se encontra a noroeste de Belém, a capital do estado, localizada na margem esquerda da baía do Guajará. Possui área de 96 km² e uma série de ilhas menores. O acesso à ilha se dá somente por meio fluvial, sendo o canal do rio Piramanha o mais importante da região, por servir de atalho para uma grande quantidade de embarcações que passam pela ilha. A cobertura vegetal é do tipo mata de várzea, com predominância do açaí (Euterpe oleracea Mat.) e outras espécies de alto valor econômico, como a andiroba, a sucuúba e o cacau (NEU et al., 2016). Nas margens dos canais, furos e igarapés, fundamental para conter o processo erosivo nas encostas e barrancos, encontra-se a aninga, uma macrófita aquática que ocorre vastamente nas várzeas amazônicas (TEIXEIRA; SIQUEIRA; CATTANIO, 2014).

Os moradores da Ilha das Onças contam com um posto de saúde e os serviços oferecidos pelos agentes comunitários de saúde. Em função da ausência de coleta de lixo, as famílias 
queimam ou enterram o lixo produzido no quintal. A água usada para o consumo humano ou nas tarefas domésticas, quando não captada diretamente do rio ou de poços, deve ser comprada em Barcarena ou Belém. O tratamento da água captada do rio pode ser feito adicionando-se a ela hipoclorito de sódio ou então fervendo-a. O sulfato de alumínio é uma alternativa muito usada pelos moradores com a finalidade de reduzir a turbidez da água (SANTOS; ARAÚJO; NEU, 2016).

As residências das famílias são predominantemente construídas de madeira, cobertas de telha de barro, enquanto a energia elétrica é obtida por meio de geradores. As condições de saneamento básico são precárias. A comunidade conta com uma única escola municipal, que atende só até o ensino fundamental II.

A comercialização do açaí constitui a principal fonte de renda das famílias residentes na ilha. Entretanto, devido à sazonalidade da produção do açaí, a pesca artesanal, a extração de palmito e do óleo de andiroba, bem como a venda de polpa de frutas contribuem para geração de renda complementar. Segundo Carmo e Neu (2016), a pesca na Ilha das Onças é uma atividade complementar para 80,5\% dos ribeirinhos, que serve tanto à subsistência quanto para fins comerciais para $73,2 \%$ dos ribeirinhos, ao passo que, para $26,8 \%$ deles, essa atividade é apenas de subsistência, sendo que, durante a safra do açaí, passa a ser uma atividade quase inexistente.

O artesanato, como uma alternativa sustentável de geração de renda, vem sendo desenvolvido, principalmente, pelas mulheres da ilha. Usando-se produtos florestais não madeireiros, como folhas, fibras, cascas, sementes, cipós e escamas de peixe, os principais produtos artesanais são as bijuterias e os artigos de decoração (NEU; ALVES, 2016).

\subsection{Amostragem e coleta dos dados}

A pesquisa ocorreu entre novembro de 2014 e dezembro de 2015. Os colaboradores foram selecionados por uma abordagem não probabilística "bola de neve" (snowball sampling) (ALBUQUERQUE; LUCENA; LINS NETO, 2010), enquanto que, para a coleta dos dados, foi aplicado um questionário adaptado (MENDONÇA; FERRAZ, 2007), que aborda informações sobre a extração e a comercialização do óleo de andiroba na comunidade da Ilha das Onças, Barcarena, Pará. O contato inicial com a comunidade ocorreu através de um líder comunitário, que indicou a primeira extratora de óleo de andiroba e recomendou o próximo, repetindo-se o processo a partir de novos incluídos. No total, 25 moradores aceitaram participar deste trabalho e assinaram um Termo de Consentimento Livre e Esclarecido (TCLE), depois de discutido e aprovado.

\section{RESULTADOS}

A coleta de dados ocorreu entre os meses de novembro de 2014 e dezembro de 2015 e, neste estudo, foram incluídos 25 moradores da comunidade da Ilha das Onças, sendo que $80 \%$ dos entrevistados pertenciam ao gênero feminino. Em relação à idade, todos os extratores de óleo de andiroba estavam na faixa etária de 40 a 50 anos. Desses, apenas uma pessoa declarou não ter frequentado a escola, entre os alfabetizados, $84 \%$ responderam que tinham o ensino fundamental incompleto.

A cadeia da extração do óleo de andiroba, conforme descrito na Tabela 1, tem início com a obtenção das sementes, que, na comunidade pesquisada, $52 \%$ dos extratores coletam na floresta e na areia da praia de água doce, enquanto os demais a obtêm em área de várzea ou nos três ambientes. Entretanto a maior abundância das sementes ocorre no período mais chuvoso. 
Tabela 1 - Descrição das etapas de obtenção do óleo de andiroba pelos moradores da comunidade da Ilha das Onças, Barcarena, Pará, Brasil

\begin{tabular}{ll}
\hline & Atividades desenvolvidas \\
\hline Locais de coleta das sementes & Floresta, várzea e areia da praia de agua doce. \\
Período de coleta das sementes & Janeiro a maio. \\
Formas de transporte das sementes & Paneiros, sacos e vasilhames plásticos. \\
Tempo de cozimento até obtenção do óleo & 42 dias \\
Método de extração do óleo & Tradicional \\
Formas de captação do óleo & Calha de alumínio, zinco e madeira. \\
Acondicionamento do óleo & Recipientes de plásticos (5 litros a $100 \mathrm{~mL}$ ). \\
Locais de comercialização & $\begin{array}{l}\text { Feira de Barcarena ou Ver-o-Peso ou na própria } \\
\text { comunidade }\end{array}$ \\
Atividades que compõem a base do sustento & $\begin{array}{l}\text { Pesca de peixe e camarão; extração de açaí e } \\
\text { falmito; coleta e extração da polpa de frutos: cacau, } \\
\text { cupuaçu e taperebá }\end{array}$ \\
\hline
\end{tabular}

Fonte: Elaborado pelos autores.

O transporte das sementes até as residências, local de extração do produto final, ocorreu em paneiros (vasilhames utilizados para transportar sementes e frutos, confeccionados de talas da palmeira de miriti), rasas (utensílios usados para transportar sementes de andiroba, fabricados de talas de arumã, miriti, jupati ou cipós), sacos e vasilhames plásticos. Segundo relatos, principalmente das mulheres, o paneiro foi considerado a melhor forma de transporte, porque permite dividir o peso da carga entre duas ou mais pessoas. A quantidade de sementes coletadas por dia foi relacionada ao local de coleta e ao regime de maré. A Ilha das Onças se localiza à margem esquerda da baía do Guajará, onde, após a maré grande, os catadores conseguiam juntar até $40 \mathrm{~kg}$ de sementes na areia da praia (Figura 1).

Figura 1-Coleta de sementes de andiroba na areia da praia na Ilha das Onças: (A) sementes depositadas na areia, arrastadas pela água durante a maré alta; (B) extratoras de óleo de andiroba coletando as sementes quando a maré baixa
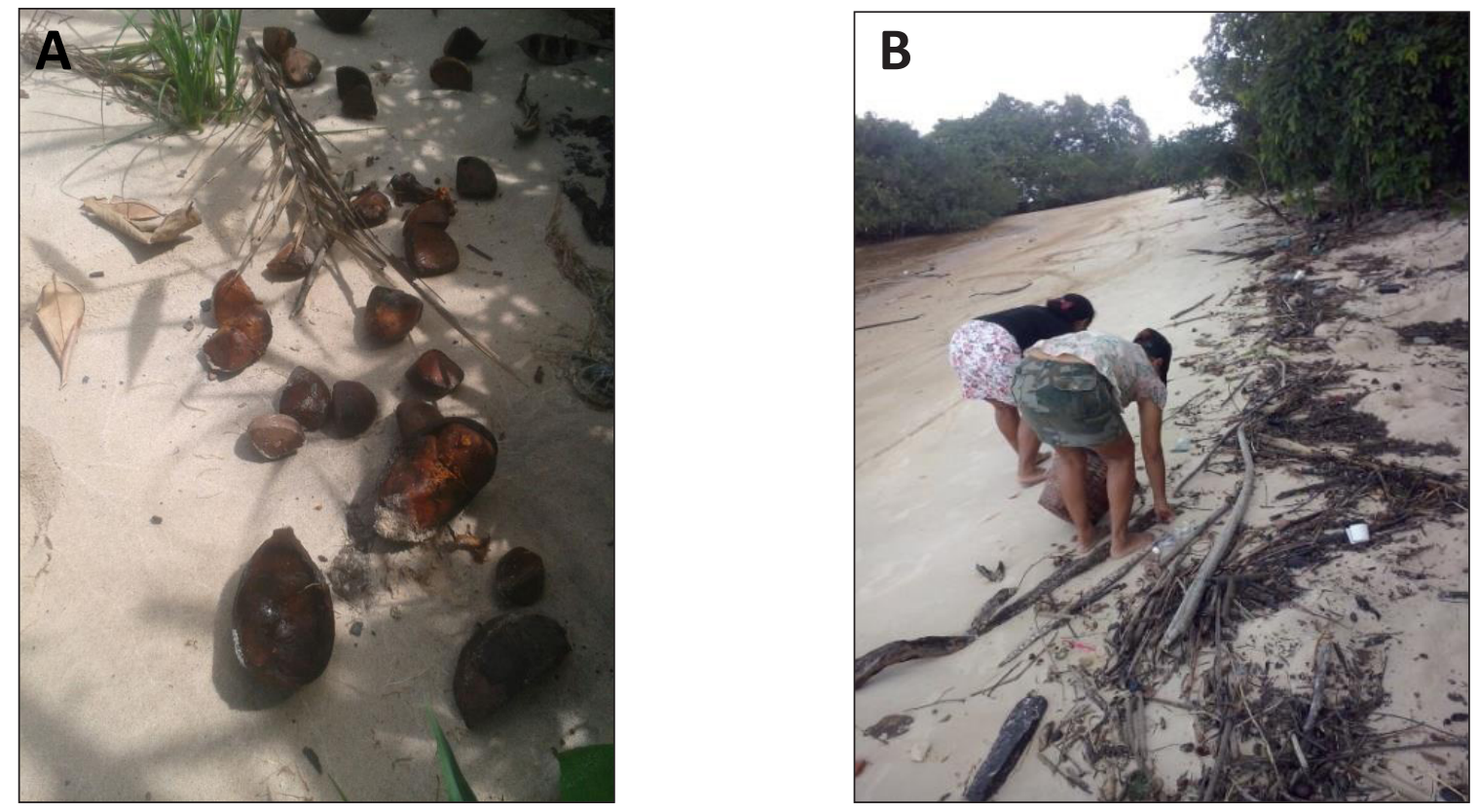

Fonte: Arquivo dos autores. 
As sementes, depois de lavadas e selecionadas, foram submetidas ao cozimento. Posteriormente, foram amassadas, moldadas em forma de bolas arredondas e, por fim, colocadas à sombra. A captação do óleo se deu em calha de zinco (60\%), e outros usavam calha de madeira ou latão. Galões de cinco litros, garrafas PET de dois ou um litro, frascos plásticos de 500 a 100 $\mathrm{mL}$ foram utilizados para armazenar o óleo de andiroba.

As formas de utilização (Tabela 2) e comercialização do óleo de andiroba variaram muito entre os entrevistados. Os extratores entrevistado usavam o óleo para cuidar da saúde, ou seja, para consumo próprio, ou o vendiam nas feiras de Barcarena, Ver-o-Peso em Belém, ou ainda para os compradores que passam na comunidade.

Tabela 2 - Frequência absoluta e relativa dos usos do óleo de andiroba pelos moradores da comunidade da Ilha das Onças, Barcarena, Pará, Brasil

\begin{tabular}{lcc}
\hline \multicolumn{1}{c}{ Usos do óleo de andiroba } & Frequência absoluta & Frequência relativa \\
\hline Cicatrizante & 8 & $32 \%$ \\
Gripe & 2 & $8 \%$ \\
Asma & 2 & $8 \%$ \\
Dor de garganta & 5 & $20 \%$ \\
Contusões & 1 & $4 \%$ \\
Inchaço & 1 & $4 \%$ \\
Dores & 2 & $8 \%$ \\
Repelente & 2 & $8 \%$ \\
Mau olhado & 2 & $8 \%$ \\
\hline
\end{tabular}

Fonte: Elaborado pelos autores.

Os moradores da llha das Onças incluídos nesta pesquisa tinham preferência por vender o óleo fora da comunidade e em pequenas quantidades (500 mL a $100 \mathrm{~mL}$ ). Entretanto apenas duas extratoras consideraram essa atividade como lucrativa. A pesca de camarão e peixe, a venda de açaí, palmito e polpa de frutas é que compõem a renda principal dessas famílias, sendo a extração do óleo de andiroba um complemento.

A extração do óleo das sementes de andiroba era tradicional, e todos os participantes desse trabalho informaram que aprenderam a técnica oralmente através da família, sendo que $80 \%$ deles responderam que aprenderam com a mãe.

As cascas das sementes foram armazenadas em um local seco, pois a fumaça obtida com a queima dessas cascas tem a função de afugentar os mosquitos, principalmente no final do dia. O equipamento usado para tal finalidade foi construído reutilizando-se latas de alumínio, que, depois de perfuradas e munidas de uma alça de arame, estão prontas para serem utilizadas, conforme ilustra a Figura 2. 
Figura 2 - Equipamento usado para queima da casca de andiroba, para produzir a fumaça, usada como repelente

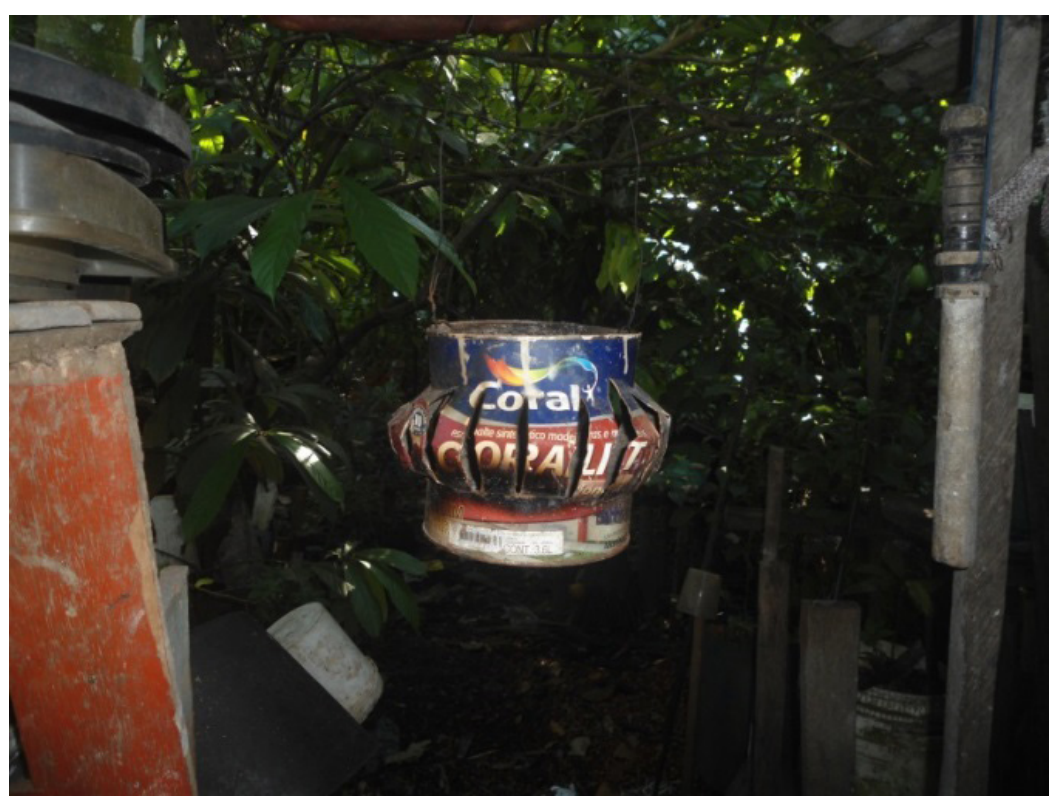

Fonte: Arquivo dos autores.

\section{DISCUSSÃO}

Os extratores de óleo de andiroba residentes na comunidade da Ilha das Onças, incluídos na pesquisa, tinham mais de 40 anos de idade, e $80 \%$ pertenciam ao gênero feminino. A predominância das mulheres na atividade de extração do óleo de andiroba foi atribuída a fatores como a demora na obtenção do produto final e o baixo retorno financeiro. No presente estudo, o tempo empregado para se obter o produto final, foi de, em média, 42 dias, tempo superior ao relatado por Mendonça e Ferraz (2007), que foi de 15 a 25 dias ao sol e de 30 dias à sombra. Destaca-se que, na comunidade da Ilha das Onças, os extratores realizavam a extração à sombra, porque o período de processamento coincide com o período chuvoso, o inverno amazônico.

As sementes foram coletadas em área de terra firme, na várzea e na areia de praia de água doce da baía do Guajará, no período mais chuvoso, nos meses de janeiro a maio. A época de produção das sementes está relacionada com questões climáticas, variando conforme a região estudada (FERRAZ; CAMARGO; SAMPAIO, 2002). No Estado do Amapá (Fazendinha), a coleta das sementes ocorre entre os meses de março a julho (NARDI et al., 2016), no Pará (Santarém e Belterra), de janeiro a agosto (SILVA et al., 2010), e no Amazonas (comunidades Manacapuru, Anamã e Silves) e ao sul do estado de Roraima, de abril a julho (MENDONÇA; FERRAZ, 2007; PEREIRA; TONINI, 2012). Uma peculiaridade da Ilha das Onças foi a coleta de sementes ao longo da areia da praia, pois, de acordo com a maré, em um único dia se pode obter de três a cinco rasas, cerca de $40 \mathrm{~kg}$, dependendo do número de pessoas coletando.

No presente trabalho, nenhum dos entrevistados citou o tipiti (um tipo de prensa de forma cilíndrica feita de palha, usado na região amazônica) como forma de extrair o restante do óleo que fica armazenado na massa, como foi citado por moradores dos municípios Manacapuru, Anamã e Silves, do estado do Amazonas (MENDONÇA; FERRAZ, 2007).

Segundo relatos dos moradores da comunidade aqui pesquisada, a cultura da extração manual do óleo de andiroba está se perdendo, pois os mais jovens não valorizam essa atividade 
devido à baixa lucratividade. Nesse aspecto, outro fator importante é que, na comunidade, há apenas uma escola municipal, que oferece até o ensino fundamental II na localidade de rio Tauerá, por isso os jovens saem para cursar o ensino médio em Barcarena ou Belém e, depois, procuram outras profissões.

A comercialização do óleo de andiroba pelos moradores participantes desta pesquisa não faz parte da base de sustento da família, pois apenas duas extratoras relataram essa atividade como lucrativa. A atividade citada como mais lucrativa e que compõe a base do sustento familiar foi a comercialização do açaí e, fora do período da safra, durante o primeiro semestre, a pesca de camarão e peixe, a extração de palmito e a confecção de artesanato passam a ser uma segunda fonte de renda. Essa pequena porcentagem de extratoras que consideram vantajosa a atividade da extração do óleo de andiroba pode estar relacionada ao domínio do conhecimento em extrair o produto, pois os entrevistados afirmaram ter aprendido a técnica através da família. Segundo Mendonça e Ferraz (2007), o isolamento geográfico das comunidades faz com que a divisão técnica e social do trabalho, geralmente, reduza-se a uma família que domina todo o processo até o produto final.

A retirada das impurezas do óleo por todos os extratores incluídos nesta pesquisa ocorreu através da filtragem. Nesse caso, passam-no por um pano fino ou pedaço de algodão e, posteriormente, o acondicionam em galões (5 litros), garrafas PET (2 litros) e frascos plásticos (1 litro ou $500 \mathrm{ml}$ ). Depois dessa etapa, seguiu-se a comercialização dentro e fora da comunidade, mas a preferência recai em vender o produto na feira do Ver-o-Peso, em Belém, e Barcarena, ou ainda aos intermediários que vão até a comunidade. O preço é muito variável, pois está relacionado com o período do ano e o local de venda. Essa falta de conhecimento de mercado e de controle de qualidade com o produto colocado à venda foi relatada por Santos e Guerra (2010), em um estudo realizado com famílias extrativistas de óleo de andiroba e copaíba.

Os moradores da Ilha das Onças destacaram que a melhor forma de vender o óleo de andiroba é fracionando em frascos de 500 a $100 \mathrm{~mL}$. Em pequenas quantidades, o produto fica mais acessível à população de baixa renda e permite negociarem o preço mais facilmente na hora da venda. Segundo o Instituto do Homem e Meio Ambiente da Amazônia (IMAZOM, 2017), o preço do litro de óleo de andiroba varia conforme as cidades, como por exemplo em Altamira, PA (R\$ 50,00 a R\$ 80,00), em Belém/PA, nas feiras do Ver-o-Peso, e da 25 de Setembro (R\$ 30,00), em Breves/PA (R\$ 40,00) e em Santana/AP (R\$97,00). Uma maneira de tornar a extração do óleo das sementes de andiroba mais rentável seria qualificar a mão de obra para conhecer outras formas de extração, além da tradicional. Outra saída seria conhecer melhor o mercado consumidor e formar associações comunitárias para obter mais vantagens na comercialização.

A fumaça obtida da queima das sementes pode ser usada como repelente para afastar mosquitos, principalmente no final da tarde, e o óleo pode ser utilizado como cicatrizante, além de atuar contra gripe, asma e dor de garganta. Existem outras indicações medicinais para o óleo de andiroba na região amazônica, relacionadas aos conhecimentos culturais, como tirar mau olhado e proteger a "mãe do corpo". Mendonça e Ferraz (2007) se referem a duas extratoras que relataram que mulheres menstruadas não devem estar no local da extração. Da mesma forma, pessoas "da mão ruim" ou invejosas não podem ver, nem tocar a massa, pois isso interferiria na quantidade de óleo produzido.

Quanto aos usos do óleo de andiroba no cuidado com a saúde, a ação cicatrizante em ferimentos na pele e dor de garganta, foi citada por $32 \%$ e $20 \%$ dos entrevistados, respectivamente. 
Esse resultado reflete a importância desse produto na medicina popular na região amazônica e reforça a importância de estudos que testem a presença de compostos biologicamente ativos.

\section{CONCLUSÃO}

O processo de extração do óleo de andiroba na comunidade da Ilha das Onças é tradicional. O produto final pode ser usado para o próprio consumo, ou para venda na comunidade local e nas feiras de Barcarena e Ver-o-Peso, em Belém, complementando a renda familiar. Quanto às formas de usos no cuidado com a saúde, a fumaça obtida da queima das cascas das sementes serve para afugentar pernilongos, enquanto o óleo é importante no tratamento de doenças e na cultura popular da comunidade.

\section{REFERÊNCIAS}

ALBUQUeRQUe, U. P.; LUCENA, R. F. P.; LINS NETO, E. M. F. Seleção dos participantes da pesquisa. In: ALBUQUerQue, U. P.; LUCENA, R. F. P.; CUNHA, L. V. F. C. (Org.). Métodos e técnicas na pesquisa etnobiológica e etnoecológica. Recife, PE: NUPEEA, 2010.

AMOROZO, M. C. M. Algumas notas adicionais sobre o emprego de plantas e outros produtos com fins terapêuticos pela população cabocla do município de Barcarena, PA, Brasil. Boletim do Museu Paraense Emílio Goeldi, Serie Botânica, v. 13, n. 2, p. 191-213, 1997.

AMOROZO, M. C. M.; GÉLY, A. Uso de plantas medicinais por caboclos do Baixo Amazonas, Barcarena, PA, Brasil. Boletim do Museu Paraense Emílio Goeldi, Série Botânica, v. 4, n. 1, p. 47-131, 1988.

BRASIL. Companhia Nacional de Abastecimento (CONAB). Diretoria de Políticas Agrícolas e Informações Superintendência de Gestão da Oferta. Proposta de preços mínimos safra 2015/2016. Brasília: CONAB, 2015. V. II.

CARDOSO, D. et al. Amazon plant diversity revealed by a taxonomically verified species list. PNAS, v. 114, n. 40, p. 10595-700, out. 2017.

CARMO, F. S. C.; NEU, V. Pesca artesanal e seus apetrechos na Ilha das Onças. In: NEU, V.; SANTOS, M. A. S.; MEYER, L. F. F.; GUEDES, V. M.; ARAÚJO, M. G. S. (Org.). Sustentabilidade e sociobiodiversidade na Amazônia: integrando ensino, pesquisa e extensão na região insular de Belém. Belém: EDUFRA, 2016. p. 15-28.

CARMO, M. B. S.; COSTA, S. M. F. Os paradoxos entre os urbanos no município de Barcarena, Pará. Revista Brasileira Gestão Urbana, Curitiba, v. 8, n. 3, p. 291-305, set./dez. 2016.

FERRARIS, F. K.; RODRIGUES, R.; DA SILVA, V. P.; FIGUEIREDO, R.; PENIDO, C.; HENRIQUES, M. D. Modulation of T lymphocyte and eosinophil functions in vitro by natural tetranortriterpenoids isolated from Carapa guianensis Aublet. International Immunopharmocology, v. 11, n. 1, p. 1-11, jan. 2011.

FERRAZ, I. D. K.; CAMARGO, J. L. C.; SAMPAIO, P. T. B. Sementes e plântulas de andiroba (Carapa guianensis Aubl. e Carapa procera D.C.): aspectos botânicos, ecológicos e tecnológicos. Acta Amazonica, Manaus, v. 32, n. 4, p. 647-61, 2002.

FERREIRA, M. C.; VIEIRA, M. L. A.; ZANI, C. L.; ALVES, T .M. A.; JUNIOR, P. A. S.; MURTA, S. M. F.; ROMANHA, A. J.; GIL, L. H. V. G.; CARVALHO, A. G. O.; ZILLI, J. E.; VITAL, M. J. S.; ROSA, C. A.; ROSA, L. H. Molecular phylogeny, diversity, symbiosis and dicover of bioactive compounds of endophytic fungi assocaited with the medicinal Amazonian plant Carapa guianensis Aublet (Meliaceae). Biochemical Systematics Ecology, v. 59, p. 36-44, 2015. 
IINSTITUTO DO HOMEM E MEIO AMBIENTE DA AMAZÔNIA (IMAZON). Preço de produtos da floresta. 2017. Disponível em: http://imazon.org.br/categorias/precos-de-produtos-da-floresta/?lang=en. Acesso em: 20 janeiro, 2018.

LEANDRO, Y. A. S.; JARDIM, I. N.; GAVILANES, M. L. Uso de plantas medicinais nos cuidados de saúde dos moradores de assentamento no município de Anapu, Pará, Brasil. Biodiversidade, Rondonópolis, MT, v. 16, n. 2, p. 30-44, 2017.

LINS, A. L. F. A.; POTIGUARA, R. C. V.; ROSA, N. A.; RIBEIRO, I. C. Macrófitos aquáticos de uma área de Barcarena, Pará, Brasil. Boletim do Museu Paraense Emílio Goeldi, Série Botânica, v. 5 n. 2, p. 135-44, 1989.

MENDONÇA, A. P.; FERRAZ, I. D. K. Óleo de andiroba: processo tradicional de extração, uso e aspectos sociais no Estado do Amazonas, Brasil. Acta Amazonica, Manaus, v. 37, n. 3, p. 353-64, 2007.

MIRANDA JÚNIOR, R. N.; DOLABELA, M. F.; DA SILVA, M. N.; PÓVOA, M. M.; MAIA, J. G. Antiplasmodial activity of the andiroba (Carapa guianensis Aubl., Meaceae) oil and its limonoid-rich fraction. Journal Ethnopharmacology, v. 142, n. 3, p. 679-83, ago. 2012.

NARDI, M.; LIRA-GUEDES, A. C.; CUNHA, H. F. A.; GUEDES, M. C.; MUSTIN, K.; GOMES, S. C. P. Artisanal extraction and traditional knowledge associated with medicinal use of crabwood oil (Carapa guianensis Aublet.) in a peri-urban várzea environment in Amazon Estuary. Evidence-Based Complementary Alternative Medicine, v. 2016, p. 1-12, 2016.

NAYAK, B. S.; KANHAI, J.; MILNE, D. M.; PEREIRA, L. P.; SWANSTON, W. H. Experimental evaluation of ethanolic extract of Carapa guianensis L. leaf for its wound healing activity using three wound models. Evidence-Based Complementary Alternative Medicine, v. 2011, p. 1-6, 2011.

NEU, V.; ALVES, F. Inclusão social das mulheres por meio da produção artesanal na Ilha das Onças. In: NEU, V.; SANTOS, M. A. S.; MEYER, L. F. F.; GUEDES, V. M.; ARAÚJO, M. G. S. (Org.) Sustentabilidade e sociobiodiversidade na Amazônia: integrando ensino, pesquisa e extensão na região insular de Belém. Belém: EDUFRA, 2016. p. 15-28.

NEU, V.; COSTA, A. N. M.; MEYER, L. F. F.; SANTOS, M. A. S. Sustentabilidade: alternativas para a região insular de Belém - a experiência na Ilha das Onças. In: NEU, V.; SANTOS, M. A. S.; MEYER, L. F. F.; GUEDES, V.M.; ARAÚJO, M.G.S. (Org.) Sustentabilidade e sociobiodiversidade na Amazônia: integrando ensino, pesquisa e extensão na região insular de Belém. Belém: EDUFRA, 2016. p. 15-28.

OLIVEIRA, P. C.; BRAGA, J. Ethnobotany of Borari-Arapiunn indigenous people, Amazon, Brazil. Journal Medicinal Plants Studies, v. 5, n. 1, p. 164-70, 2017.

PENIDO, C.; CONTE, F. P.; CHAGAS, M. S.; RODRIGUES, C. A.; PEREIRA, J. F.; HenRIQUeS, M. G. Antiinflammatory effects of natural tetranortriterpenoids isolated from Carapa guianensis Aublet on zymosan-induced arthritis in mice. Inflammation Research, v. 55, n. 11, p. 457-64, nov. 2006.

PENIDO, C.; COSTA, K. A.; PENNAFORTE, R. J.; COSTA, M. F.; PEREIRA, J. F.; SIANI, A. C.; HENRIQUES, M. G. Anti-allergic effects of natural tetranortriterpenoides isolated from Carapa guianensis Aublet on allergeninduced vascular permeability and hyperalgesia. Inflammation Research, v. 54, n. 7, p. 295-303, jul. 2005.

PEREIRA, M. R.N.; TONINI, H. Fenologia da andiroba (Carapa guianensis, Aubl., Meliaceae) no sul do Estado de Roraima. Ciências Florestal, Santa Maria, v. 22, n. 1, p. 47-58, jan./mar. 2012.

PEREIRA, T. B.; SILVA, L. F. R.; AMORIM, R. C. N.; MELO, M. R. S.; SOUZA, R. C. Z.; EBERLIN, M. N.; LIMA, E. S.; VASCONCELOS, M. C.; POHLIT, A. M. In vitro and in vivo anti-malarial activity of limonoids from the residual seed biomass from Carapa guianensis (andiroba) oil production. Malarial Journal, v. 13, p. 317, 2014. 
PLOWDEN, C. The ecology and harvest of andiroba seeds for oil production in the Brazilian Amazon. Conservation Society, v. 2, n. 2, p. 251-72, 2004.

PROPHIRO, J. S.; DA SILVA, M. A.; KANIS, L. A.; DA ROCHA, L. C.; DUQUE-LUNA, J. E.; DA SILVA, O. S. First report on susceptibility of wild Aedes aegypti (Diptera: Culicidae) using Carapa guianensis (Meliaceae) and Copaifera sp. (leguminosa). Parasitology Research, v. 110, n. 2, p. 699-705, fev. 2012.

SANTOS, A. J.; GUERRA, F. G. P. Q. Aspectos econômicos da cadeia produtiva dos óleos de andiroba (Carapa guianensis Aubl.) e copaíba (Copaifera multijuga Hayne) na floresta nacional do Tapajós - Pará. Floresta, Curitiba, PR, v. 40, n. 1, p. 23-28, jan./mar. 2010.

SANTOS, M. A. S.; ARAÚJO, J. G. A.; NEU, V. Perfil socioeconômico de famílias ribeirinhas da llha das Onças, região insular de Belém. In: NEU, V.; SANTOS, M. A. S.; MEYER, L. F. F.; GUEDES, V. M.; ARAÚJO, M. G. S. (Org.) Sustentabilidade e sociobiodiversidade na Amazônia: integrando ensino, pesquisa e extensão na região insular de Belém. Belém: EDUFRA, 2016. p. 15-28.

SANTOS, M. N.; CUNHA, H. F. A.; LIRA-GUEDES, A. C.; GOMES, S. C. P.; GUEDES, M. C. Saberes tradicionais em uma unidade de conservação localizada em ambiente periurbano de várzea: etnobiologia da andirobeira (Carapa guinensis Aublet). Boletim do Museu Paraense Emílio Goeld. Ciências Humanas, Belém, PA, v. 9, n. 1, p. 93-108, jan./abr. 2014.

SILVA, E. N.; SANTANA, A. C.; SILVA, I. M.; OLIVEIRA, C. M. Aspectos socioeconômicos da produção extrativista de óleos de andiroba e de copaíba na floresta nacional do Tapajós, Estado do Pará. Revista Ciências Agrárias, v. 53, n. 1, p. 12-23, jan./jun. 2010.

SILVA, V. P.; OLIVEIRA, R. R.; FIGUEREDO, M. R. Isolation of limonoids from seeds of Carapa guianensis Aublet (Meliaceae) by high-speed countercurrent chromatography. Phytochemical Analysis, v. 20, n. 1, p. 77-81, jan./feb. 2009.

SOUZA, A. P. S.; LISBOA, R. C. L. Musgos (Bryophyta) na llha Trambioca, Barcarena, PA, Brasil. Acta Botanica Brasilica, v. 19, n. 3, p. 487-92, 2005.

TEIXEIRA, D. F. F.; SIQUEIRA, B. S.; CATTANIO, J. H. Importância da aninga (Montrichardia linifera) na retenção de sedimentos na Baía do Guajará, PA. Revista Estudos Ambientais, v. 16, n. 12, p. 6-19, jul./dez. 2014.

\section{Sobre autores:}

Ronaldo Lopes de Sousa - Doutorado em Biologia de Agentes Infecciosos e Parasitários pela Universidade Federal do Pará. Professor Adjunto I da Universidade Federal do Pará, curso de Licenciatura Educação do Campo-Ciências Naturais. Possui experiência na área de Animal, com ênfase em Ciências Biológicas, Etnobotânica, Virologia e Biologia Molecular. E-mail: ronaldosousa@ufpa.br, Orcid: http://orcid.org/0000-0002-5440-2959

Abdi Ueke da Silva Miranda - Graduando do Curso de Licenciatura em Educação do Campo na Universidade Federal do Pará, campus de Abaetetuba. Professor da rede Básica de Ensino do Município de Barcarena, PA. E-mail: lopesufpa.15@gmail.com, Orcid: http://orcid.org/0000-0002-5466-8546

Yvens Ely Martins Cordeiro - Doutorado em Ciências Agrárias, área de concentração Agroecossistemas da Amazônia, pelo Convênio UFRA/EMBRAPA. Mestrado em Ciências Agrárias, Área de Concentração em Biologia Vegetal Tropical, pela Universidade Federal Rural da Amazônia. 
Graduação em Ciências Biológicas pela Universidade Federal do Pará (UFPA). Professor Adjunto II da UFPA, coordenador do Curso de Licenciatura em Educação do Campo e diretor da Faculdade de Formação e Desenvolvimento do Campo, vinculada ao Campus Universitário de Abaetetuba/UFPA. Professor Adjunto I na Universidade Federal do Pará. Professor no Curso de Licenciatura no Curso Educação do Campo. E-mail: yemcordeiro@ufpa.br, Orcid: http://orcid.org/0000-0003-0596-002X

Maria das Graças Pereira - Doutoranda do Programa de Pós-Graduação em Agriculturas Amazônicas / Doutorado em Agriculturas Familiares e Desenvolvimento Sustentável (DAFDS) no Instituto Amazônico de Agriculturas Familiares na Universidade Federal do Pará (UFPA), campus Belém. Mestrado em Ciências Biológicas pela Universidade Federal Rural da Amazônia e Museu Paraense Emílio Goeldi. Especialização em Educação do Campo e Extensão Rural pela UFPA, campus Abaetetuba. Graduação em Ciências Biológicas pelo Instituto Federal de Educação Ciência e Tecnologia do Pará - Campus Abaetetuba. Professora Assistente no curso de Licenciatura em Educação do Campo na UFPA. E-mail: pereiramariabio@gmail.com, Orcid: http://orcid.org/0000-0003-1905-6605 
